\section{OROFACIAL PAIN}

\section{Oral and maxillofacial surgery in patients with chronic orofacial pain}

Israel HA, Ward JD et al. J Oral Maxillofac Surg 2003; 61: 662-667

Misdiagnosis frequently led to treatment failure.

Some patients have orofacial pain which is difficult to diagnose, and consequently treatment may fail. Over a 2 year period, 120 patients (75\% female; mean age 49 yrs) with a history of pain for a mean 6.75 yrs, and having seen on average 6 previous specialists, were seen at a New York facial pain clinic.

A single clinician from a multidisciplinary team recorded each patient's history and conducted an examination, with other clinicians present. The team immediately met in conference, made diagnoses and recommended appropriate treatment. Diagnoses included: myofascial pain (50\%), atypical facial neuralgia (40\%), depression (30\%), TMJ synovitis (14\%), TMJ osteoarthritis (12\%), trigeminal neuralgia (10\%) and TMJ fibrosis (2\%).

In 38 patients, previous treatment had been performed: endodontics (30\%), exodontia (27\%), apicoectomy (12\%), TMJ surgery (6\%), neurolysis (5\%), orthognathic surgery (3\%) and debridement of bone cavities (2\%). In more than half of patients, surgical treatment had clearly exacerbated pain. In 6 patients, gross misdiagnosis led to serious sequelae: in one, a parotid adenocarcinoma treated as a TMJ problem for 13 months was found to be inoperable.

doi:10.1038/sj.bdj.4810785

\section{ORTHODONTICS}

\section{Constant versus dissipating forces} in orthodontics: the effect on initial tooth movement and root resorption

Weiland F. Eur J Orthod 2003; 25: 335-342

Constant forces moved teeth quicker but led to greater root resorption.

In 27 patients of mean age 12.5 yrs, 90 premolars scheduled for orthodontic extraction were actively moved buccally (84) or used as controls (6). Test teeth were treated in pairs: on one side a stainless steel wire was used (initially high but rapidly declining force), but on the other, a superelastic arch wire (initially lower force of $1 \mathrm{~N}$ but constant from 4 to $0.25 \mathrm{~mm}$ deflection).

The superelastic wire moved teeth significantly more 3.5 $\mathrm{mm})$ than the stainless steel wire $(2.3 \mathrm{~mm})$ and tipped further buccally. On extraction, one small resorption was found on a control tooth root with confocal microscopy, but more were found on test teeth. Mean depth of resorption did not differ between the test groups, but a significantly greater area was affected in the superelastic group.

\section{doi:10.1038/sj.bdj.4810786}

\section{PERIODONTICS}

\section{Periodontitis and perceived risk for perio- dontitis in elders with evidence of depression}

Persson GR, Persson RE et al. J Clin Periodontol 2003; 30: 691-696

A history of depression was associated with a number of diseases and with tooth loss, but not with current periodontitis.

There is evidence that periodontitis and depression may be associated in older people. In this study, 701 subjects aged 60-75 yrs in Seattle responded to questionnaires and were periodontally examined. Periodontitis was diagnosed in 49\%, 55\% had never smoked and 22\% currently smoked. A history of depression was reported by 20\%; but evidence of clinical depression was given only by $10 \%$.

Subjects reporting depression had significantly more strokes, myocardial infarcts, hypertension, osteoarthritis, chronic pain and osteoporosis than subjects without this history, but the 2 groups had similar experience of periodontitis. Tooth loss, however, was 30\% greater in the depressed group, which might reflect periodontitis during a past bout of depression.

doi:10.1038/sj.bdj.4810787

\section{ORAL SURGERY}

\section{Can third molar surgery improve quality of life? A 6-month cohort study \\ McGrath C, Comfort MB et al. J Oral Maxillofac Surg 2003; 61: 759-763}

Quality of life (QoL) deteriorated immediately after surgery, but was improved later.

This was a prospective study of QoL in 100 patients undergoing surgery to remove a single mandibular third molar. Patients completed 2 questionnaires (Oral Health Impact Profile-14, and UK Oral Health-related QoL measure) on the day of surgery and kept a recovery diary for 7 days. They were then followed up for 6 months. Twelve subjects dropped out of the study.

Both questionnaires indicated deterioration of QoL in the week after surgery, but by 1 month, there was an improvement which continued to 6 months. Around 20-30\% of subjects experienced improvement in a wide range of QoL factors, such as comfort, halitosis, oral, individual and social activities. The authors make the point that these improvements were likely to be clinically significant, and the main effect was to reduce the burden of negative experiences associated with the teeth which were removed.

doi:10.1038/sj.bdj.4810788 